Estudios sobre armas antiguas, arte militar $\mathrm{y}$ vida cultural en oriente y occidente

XXXVIII (2018), pp. 177-197

ISSN: 0436-029X

https://doi.org/10.3989/gladius.2018.10

\title{
EL FACTOR HUMANO EN LA DEFENSA DE GIJÓN FRENTE AL AUSTRACISMO. 1700-1712*
}

THE HUMAN FACTOR IN THE DEFENSE OF GIJON AGAINST AUSTRACISM. 1700-1712

POR

\author{
Evaristo C. Martínez-Radío Garrido**
}

\section{RESUMEN - ABSTRACT}

Se trata de analizar la respuesta del Ayuntamiento de una importante villa marinera del Cantábrico ante las urgencias de la Guerra de Sucesión, destacando las distintas actitudes de sus elites combinando los ámbitos defensivo, económico y social a través de un estudio exhaustivo de las fuentes primarias. Así se llega a observar distintos comportamientos, propuestas y respuestas oficiales en la relación con el gobierno del Principado y la Corona, según los temores o tranquilidad de la población, en el contexto de lo que fue una molesta carga, tanto en levas como económica, a la que hubo de resignarse.

This article analyzes the response of the Town Hall of an important Cantabrian sea-faring town to the urgencies of the War of Spanish Succession. It highlights the different attitudes and measures taken by its elites, combining the defensive, economic and social spheres through an exhaustive study of the primary sources. We thus observe different behaviors, proposals and official answers in the relationship with the government of the Principality and the Crown. These were dependent on the fears or tranquility of the town in the context of what was a reluctantlyaccepted burden, both in levies and economic terms.

\section{Palabras Clave - Keywords}

Guerra de Sucesión; milicias; levas; Asturias; hidalgos; siglo XVIII; pertrechos.

War of the Spanish Succession; local militia; levies; Asturias; noblemen; 18th Century; supplies.

\section{Cómo CITAR ESTE ARTículo / Citation}

Martínez-Radío Garrido, E. (2018): «El factor humano en la defensa de Gijón frente al austracismo. 17001712». Gladius, 38: 177-197. https://doi.org/10.3989/gladius.2018.10

${ }^{*}$ Este trabajo responde al proyecto «Prisoners of war between the Bourbon nations and the United Kingdom during the 18th Century: ways of life and humanity in misfortune» («PriWa»), con fondos del programa de investigación e innovación de la Unión Europea Horizon 2020, Marie Sklodowska-Curie (código de acuerdo 746995).

${ }^{* *}$ Marie Curie Research Fellow en la Universidad de Warwick, School of Modern Languages and Cultures, e.martinez-radio-garrido@warwick.ac.uk / ORCID iD: http://orcid.org/0000-0001-7015-9680.

Abreviaturas utilizadas: para Archivo de la Academia de Genealogía y Heráldica de Asturias, AAGHA; para Archivo Histórico de Asturias, AHA; para Archivo Municipal de Gijón, AMGj; para National Archives (Kew-Londres), NA. 


\section{INTRODUCCIÓN}

Es común que al hablar de Historia Militar se haga desde la distancia, a modo general. Pero en realidad debemos tratar con hombres que la protagonizaron, esto es, de vidas que estuvieron en juego. No obstante, no nos damos realmente cuenta de ello a no ser que la personalicemos. Es decir, que pensemos que nos toque vivir lo que referimos y, por tanto, que es nuestra vida la que podría estar en riesgo. Así valoraremos mejor los hechos. Este es un punto que actualmente puede costar más al hablar desde la distancia temporal. Pero tal distancia no es tanta si nos referimos al Antiguo Régimen que aquí abordamos. Es decir, en estas épocas pretéritas se coexistía con la guerra, como una desagradable parte más que estaba en las posibilidades que les pudiera tocar vivir a una persona o una comunidad. Esto es, ver y comprobar cómo afecta tanto a uno mismo como a vecinos y familiares (sean levados, saqueados, desaparecidos, cautivos, mutilados o fallecidos, por ejemplo) junto a la amenaza de incursiones o ataques inesperados. De ahí la necesidad de las milicias. De hecho, en tiempo de conflicto la población continuaba -y debía continuar- con sus quehaceres cotidianos, preocupándose realmente por el mismo en caso de presencia del enemigo o de una leva. Otro punto más, relativo y aparte, sería el de las fidelidades a una u otra causa, ya que debía defender a uno u otro rey sin capacidad de elección. Es decir, a quién les gobernara y sin otro modelo de gobierno.

En este sentido, aunque no nos centraremos en todas las variantes, también es evidente que no se puede hablar de historia militar sin conocer los factores económico-sociales que la sustentan, sea en modo amplio o incluso particular, como es el caso de este trabajo. Siempre teniendo en cuenta que las fuentes oficiales reflejan lo que «deben» o quieren reflejar, más cuando se trata de testimonios, por lo que no necesariamente tiene por qué tratarse de toda la verdad, sino que también puede estar maquillada, buscando tanto no comprometer a quien la exponga y/o bien influir en las personas a quién van dirigidas. Es el caso evidente de las elites locales. Pero, aún así, lo importante es que nos reflejan unos hechos, zozobras, testimonios de primera mano... una petit histoire desde abajo que, unidas a otras, nos dan una imagen más veraz de la grande histoire al conocer sus porqués y entresijos.

Una vez apuntado esto, entonces la sensación de seguridad para un hombre de costa en la Edad Moderna se veía condicionada tanto por las estructuras defensivas que lo protegían como por contar con el importante factor humano, mejor bien pertrechado y preparado para hacer frente a aquellas incursiones inesperadas del enemigo del momento y proteger tanto su integridad física o la de sus seres cercanos como su modo de vida. El litoral del Principado de Asturias estuvo sufriendo esta molesta presencia durante toda la Edad Moderna, pero a pesar de ello parecía que no contaba con las mejores medidas defensivas, sean edilicias como tal factor humano para afrontar una amenaza de cierto calado. Aquí se incluye Gijón, donde sí es cierto que se habían construido algunas defensas y Carlos I y Felipe II ya habían mostrado su interés en cuanto a mejorar estas así como los pertrechos de los vecinos. Hasta la paz de Riswick (1697), se adoptaron diversas medidas, pero que no podían hacer frente a un conflicto y un ataque contundente. De hecho, siguiendo a Rato y Roces, la villa no estuvo bien artillada hasta tiempos de Carlos III'.

Por último, Gijón, al igual que el resto de Asturias, hubo de contribuir en diversos gastos, tanto propios como de la guerra, que le llevó a endeudarse e imponer arbitrios o censos.

\footnotetext{
1 Para contexto general, vid. Porras Gil, 1995: 95-105; Bonet, 1970a: 150; Bonet, 1970b: 232; Adaro Ruiz-Falco, 1979: 169; Ovies Ruiz, 1970: 187-190; Suárez-Inclán, 1970: 10; García San Miguel, 1980: 222, 223; Rato y Roces, 1980: 165; Bellmunt y Traver, 1980: 346, 347; Canella Secades, 2000: 483; González Llanos y González Llanos, 2000: 99, 100; Peribáñez Caveda, 2010: 20, 21; Martínez-Radío, 2007: 205-230; Martínez-Radío, 2003: 383-402; Fernández Martín, 1977: 795- 821.
} 


\section{AFRONTANDO EL RETO}

Ya en 1701, antes del estallido oficial del conflicto, se estableció la batería de salvas y se construyó para su servicio y almacén el edificio que se llamó «Casa de las piezas». La Guerra de Sucesión y el temor a una posible invasión reactivó las medidas defensivas, más o menos improvisadas en varios concejos, destacando el caso que nos ocupa que, a pesar de los antecedentes, parecían mostrar graves carencias ${ }^{2}$. Adoptará las suyas propias a la par que solicitaba ayuda a la Corona y a la Junta General del Principado. Se construyeron en la Atalaya (Santa Catalina), Garita, Arnao y San Lorenzo, parapetos, fortines y otras construcciones defensivas a costa de la villa y se movilizaron y se pusieron al día sus milicias. Nos centramos, sin limitarnos, en este segundo caso: aquellas personas que físicamente deben hacer frente al enemigo. Lo vemos a continuación.

\subsection{EL AÑo 1703}

A pesar de lo apuntado, la guerra parece que no tuvo eco grave hasta el año 1703, cuando realmente cundirá el nerviosismo. Ya habiendo abrazado institucionalmente la causa del pretendiente Borbón, a mediados de septiembre del año anterior se había recibido una carta-orden del presidente del Consejo de Castilla, Manuel Arias, dando cuenta del desembarco en Andalucía de las tropas aliadas y solicitando ayuda al Principado con medios y/o soldados ${ }^{3}$. Es entonces cuando parece que empieza a abrirse la idea de que Asturias realmente estaba más cerca del territorio enemigo que Andalucía y, por tanto, recela de un posible ataque. Se responderá con una suma de 2000 doblones, equivalente a 300 soldados, evitando así sacar mozos de la tierra. Entonces saldrán a la luz alarmantes carencias defensivas: más de 18 puertos sin fortificación, artillería ni munición y unas milicias formadas con lugareños mal preparados y muy pobres y, por tanto, mal armados y con falta de munición. En este contexto, a finales de enero el capitán de la villa Gregorio Jovellanos expone en el Ayuntamiento que se podría sufrir una agresión por parte de ingleses y holandeses, añadiendo el mal estado de las fortificaciones como esa carente preparación miliciana ${ }^{4}$. La villa, temiendo ser invadida, acudirá con tales cuitas a la Diputación para solicitar ayuda y conseguir pertrechos. ${ }^{5}$. Mostrando un marco de indefensión regional, expone su vulnerabilidad y que podría ser tomada con menos de 2000 hombres, cons-

2 El caso de Gijón en este período ha sido estudiado por Evaristo C. Martínez-Radío, sobre todo en su obra La Guerra de Sucesión y Asturias (2009), destacando más concretamente los apartados «Los temores de Gijón» y «El Gijón de la Guerra» (vid. aquí pp. 119-123 y 165-184). Entendemos que es el autor y el estudio más completo y del que debemos partir, si bien enriqueciendo algunos aspectos para que, efectivamente, el presente sea una aportación, como es lógico. Tras el cual nos percatamos que surgieron algunos artículos o monografías bebiendo del mismo aunque con distinta originalidad, por así decir. Por poner dos ejemplos distintos, aún con alusiones, un caso es el de Dongil Sánchez en Tiempos Modernos. Revista electrónica de Historia Moderna [en línea] vol. 7, núm. 23 (2011), al apuntar repetidamente como primera persona o indirectamente lo ya expuesto en aquél; en este sentido no podemos hablar de aportación original. Por su parte Artemio Mortera Pérez, en lo que hace a las defensas costeras, parte de la citada referencia mostrando claramente, salvo excepción, el origen de la información y continúa hasta época contemporánea en Mortera Pérez, 2010.

3 AHA, Libros de Actas Históricas de la Junta General del Principado, tejuelo VIII, diputaciones de 5 de febrero y de 11 de abril de 1701, ff. 191 v.- 192 v.

4 AMGj, Libro de Acuerdos de 1703, ff. 1 r.- 2 v. y 82 v. AHA, Libros de Actas Históricas..., tejuelo VIII, doc. cit., ff. 222 r.- 224 v.

5 Compuesta y designada por miembros de la Junta General actuando cuando ésta no estaba reunida. Entre sus atribuciones figuraba lo referente a medidas defensivas y militares, como es lógico. Al respecto hay diferentes autores que aluden a tal relación, como Alfonso Menéndez González (1992), Marta Friera (2003), Miguel de la Villa (1909), Francisco Tuero Bertrand (1976, 1978), José Caveda Nava (ed. 1989) o el Vizconde de Campo-Grande (1916), entre otros. 
tituyéndose después en cabeza de puente desde la que atacar otros puntos e, incluso, progresar hacia el interior de Castilla sin mayor inconveniente ${ }^{6}$.

\subsection{Estado DE LAS Milicias}

Nos detenemos brevemente en tal alegato, pues debemos preguntarnos entonces con qué podría ser rechazado tal número de invasores. Y es que, evidentemente, aparte del paisanaje y de los marineros que tendrían que proteger el litoral, debería la villa (y el Principado) contar con la protección de los cuerpos de milicias, las primeras en hacer frente al invasor ${ }^{7}$. Ya aludimos a su mal estado. Mientras el Principado solicita ayuda a la Corona, envía un memorial al monarca en febrero de 1703 definiéndole su situación de indefensión ${ }^{8}$, escaso de artillería y fortificaciones para la costa, pero se evidencia que esta no hacía mucho caso ${ }^{9}$. Los asturianos buscan sus propios pertrechos y medidas defensivas, destacando el caso de Gijón ${ }^{10}$. Por tal memorial se evidenciaban grandes deficiencias en las milicias que, divididas en tres sargentías mayores y repartidas en 132 compañías, seguramente más en teoría que en la práctica, deberían sumar 13200 hombres, a razón de 100 por cada una. Es probable que se trate de una cifra exagerada pues serían muchos y si estuvieran bien entrenados tendrían una capacidad de resistencia a considerar. En tanto, el 2 de abril de 1703 Gregorio Jove Llanos propone la creación de una compañía propia de Gijón, que no prospera. Lo tratamos unas líneas más adelante. Respecto a la población de la villa contaría con unas 3284 almas en 1704, subiendo a 3352 en seis años más tarde ${ }^{11}$.

Entre tanto, el Sargento Mayor de la villa, Fernando de León Falcón, el 26 de marzo avisa de la presencia enemiga en la costa asturiana, solicitando que se revisen las construcciones defensivas y artillería. Tales inquietantes noticias tendrán más gravedad ante el testimonio del alférez mayor de Colunga, Lope de Junco, dando cuenta de tal presencia y de que una fragata holandesa había bombardeado la villa de Lastres, siendo los propios vecinos quienes hubieron de hacerle frente con un cañón que habían tomado de un barco francés que había llegado a puerto precisamente escapando del enemigo ${ }^{12}$.

La villa mejorará sus defensas, pero, centrándonos en lo que atañe al factor humano, en mayo se estudia realizar una fortificación más sólida de la villa. El Ayuntamiento acuerda valerse de la compañía de milicias del capitán Antonio Menéndez de Castro para el reconoci-

\footnotetext{
6 AHA, Libros de Actas Históricas..., tejuelo VIII, doc. cit., f. 220 r. Martínez-Radío, 2008a: 256. La situación de indefensión y los temores más o menos infundados de una posible invasión se repetirán en la centuria. Vid., por ejemplo, González Sánchez, 2005: 661-672.

7 Para el caso en un marco amplio, relacionando Asturias con la política y contextos del momento, vid. MartínezRadío, 2013.

8 A la par, tanto los concejos como el propio gobierno asturiano buscarán solucionar o mejorar sus medidas defensivas, incluso en otras regiones. Vid. Martínez-Radío, 2009: 149 y 191-203.

9 Se descartaba que fuera un objetivo militar, al menos a priori. Así lo cree el marqués de Valdecarzana y se expone en la Diputación de 22 de marzo de 1703. AHA, Actas Históricas de la Junta...., t. VIII, doc. cit. ff. 241 v.- 242 v. El propio Felipe V dirá en 1725 que Asturias, en caso de ser invadida no sería rentable al enemigo por la carestía de alimentos, aparte de que su orografía dificultaría su entrada. Además, según él, contaba con milicias y artillería suficiente. Esto último probablemente se puede comprender mejor si la defensa asturiana fue mejorando a raíz del conflicto sucesorio. AHA, signatura 8, reseña «Órdenes, Cartas Órdenes y Provisiones de Su Majestad y del Consejo de Hacienda sobre introducción de sal, aumento de su precio, imposición de arbitrios sobre ella y otras tocantes al mismo ramo», f. $49 \mathrm{v}$.

10 El caso de Gijón es más que evidente, pero no es el único.

11 Según Peribáñez Caveda, 2010: 42.

12 Vid. Álvarez-Buylla, 1970: 225; Canella Secades, 2000: 483. AHA, Actas Históricas de la Junta..., t. VIII, doc. cit., ff. 264 v.- 265 v.
} 
miento del terreno, ver los lugares más apropiados para emplazar la artillería y con ellos qué obra habría que realizar. De no contar con suficientes hombres, se llamarían los de otras compañías y todo ello hasta que llegara un ingeniero que se había solicitado a la Corona ${ }^{13}$.

Ya en agosto, el regidor Gaspar Jove Bernardo se queja ante la falta de pertrechos de los vecinos, tanto de la villa como algunos del concejo, frente a un posible ataque, a pesar de que el año anterior se había acordado proveerles con arcabuces, pólvora, frascos, balas y cuerda. Se detecta una preocupante escasez de pólvora, teniendo en cuenta que de aquella no la había en venta en Gijón. Del mismo modo, que había muchos mozos («sin estado») desarmados. Hemos de destacar entonces que era de la obligación de los milicianos gijoneses estar pertrechados y con munición y no estaban preparados a pesar de haber tenido tiempo para ello. Había que hacerse con dicha pólvora y distribuirla. Es por este motivo que Jove Bernardo consideró por conveniente que todos aquellos que habían llevado arcabuces y pólvora la restituyeran y compraran cada uno la porción que debía. Esto a pesar de que el vecino José Martínez Valdés tenía 20 quintales en venta, pero se padecía escasez para proveer el almacén de la villa y la artillería. Entonces, se dispuso averiguar quiénes debían pólvora por haberla tomado prestada del almacén para su restitución. No obstante, el Ayuntamiento acabó comprando esos días la que le sobraba (o parte) a tal vecino a expensas de los propios ${ }^{14}$.

El Ayuntamiento tarda en hacerse con la pólvora y los pertrechos necesarios. Sabemos que había llegado a un acuerdo con otro vecino, Pedro Condres Argüelles, para que se hiciera con 40 quintales de pólvora, munición y cuerda. A mediados de septiembre solo había podido proporcionar 21 y pedía más dinero para cumplir con tal encargo, lo que, obviamente, no fue del gusto de los capitulares. Con todo, se acordó repartir la que hubiera entre los milicianos ${ }^{15}$. Los encargados de la escritura con este vecino habían sido Gregorio Jove Llanos y Carlos Ramírez de Jove ${ }^{16}$, a quienes les dice que traerá los pertrechos de San Sebastián en unos ocho días. De esta manera busca evitar el malestar del Ayuntamiento, teniendo presente tanto las dificultades a causa de los grandes gastos afrontados por el mismo el año anterior como los que tenía en ese momento por reparaciones en el muelle ${ }^{17}$. A finales de noviembre se había gastado en pólvora y munición más de 40.000 reales, con lo que ya debía estar allí ${ }^{18}$.

13 AMGj, Libro de Acuerdos de 1703, ff. 46 r.- 47 v.

14 Ibid., ff. 77 r.- 78 v.

15 Sesión del Ayuntamiento del día 12. El juez de la villa conmina a que Condres, en caso de tener tal material, lo llevara a la villa, por el que se le daría un dinero. Ibíd., ff. 86 r- 89 v.

16 Caballero de la Orden de Calatrava y comisario de Artillería del Principado a partir de 1707. Vid. Pérez de Rada, 1999: 153 y 234; Samaniego Burgos, 1979: 234 y 236.

17 A la par que comenta que no es su intención cansar a los capitulares de la villa a causa del dinero de la compra del material, se compromete a obtener los certificados correspondientes que demuestren que no tiene intención de engaño y que, una vez traído, no pediría dinero hasta marzo o abril. De la misma manera, que el importe de esta cantidad lo emplearía en la carencia de la pólvora y bala que constaba en la escritura. Una vez cumplido el contrato, solicita satisfacción íntegra por Gijón. AMGj, Libro de Acuerdos de 1703, ff., 90 r. y ss.

18 Sesión del Ayuntamiento de 23 de noviembre. Por otro lado, también se construyó un fortín detrás de la iglesia parroquial, pues a mediados de octubre se dan 883 reales y 8 maravedís al capitán de milicias Pedro de Valdés, por los gastos que había tenido por su construcción. Este capitán era el encargado de mantener preparadas tanto la artillería y munición como las defensas en general. Ibid., f. 101 v. AAGHA, Fondos del Archivo Revillagigedo, Casa de Valdés, carpeta 160, carpetilla Memorial de don Pedro de Valdés Miranda, vecino y regidor de Gijón y capitán de Milicia de dicha villa $y$ de su puerto, exponiendo los servicios prestados, con presentación de testigos, con motivo de la pretensión por parte de don Carlos Ramírez de Jove, de la Orden de Calatrava, de que se le nombre Comisario Provincial de la Artillería del Principado de Asturias. 1706, ff. 1 r.- 3 r. 


\subsection{LAS LEVAS EN GiJÓN}

Un problema grave para la villa, como para el resto del Principado, era aportar soldados, más de forma forzada que voluntaria, pues conllevaba problemas económicos y sociales y sanciones en caso de retrasar los plazos. El momento de máxima tensión se producirá precisamente en 1703 a raíz de la creación del Tercio del Principado ${ }^{19}$, algo de lo que la villa intentó librarse, pues había que completarlo periódicamente.

El 22 de marzo de ese año se da cuenta de la solicitud de soldados en vista de la invasión en Andalucía. A Gijón y su concejo les tocan once aptos que debían estar en Oviedo el 1 de abril. El Ayuntamiento acuerda cumplir y poner la bandera en la parte acostumbrada el día 25 por si hubiera algún voluntario, al que le darían 2 doblones por el enganche y 3 diarios para su sustento hasta que se entregara en la capital asturiana. Pero los siempre presentes problemas respecto a las levas no tardarán en aflorar a pesar de la voluntad, más o menos sincera, de colaborar en este punto. Dos días después de recibir las instrucciones, el juez ordinario de Gijón, Domingo Argüelles de Condres, expone que no iba a ser posible cumplir en tan poco tiempo. $\mathrm{Al}$ inconveniente se sumaba que la villa no había podido reunir cuatro soldados y que, aquellos que se encontraban presos para servir, se dudaba si debían ir sin ser precedidos del preceptivo sorteo «que se dispone por dichas reales órdenes». Es decir, se plantean qué método de leva seguir: sorteo o elección, lo cual retrasará el cumplimiento de la orden. Pero el problema de los voluntarios era sin duda real, porque la villa tratará de enganchar un voluntario que había sentado plaza pero era natural de León ${ }^{20}$. Sin duda como incentivo, se ofrecieron 3 reales de vellón a cada levado y cada voluntario al día. Mientras los dos voluntarios que tenía asentados debían hacer frente a la inspección médica al uso para asegurarse de que pasarían el filtro de Oviedo; de no ser así, se les debía despedir. Esto deja claro que sí se buscan hombres aptos para el servicio, pero que era un problema. El día 29, además de dar 3 reales a los nuevos soldados, el atractivo al que se presentara voluntario ascendió a una casaca, una montera de paño de arreras y una camisa ordinaria. El problema y desesperación del Ayuntamiento es evidente, no solo ya por el dinero e incluso ropa ofrecida como incentivo. También se acordó admitir por soldado a un mozo que se había presentado voluntario en la villa, pero con la condición de que, de no ser pasado por el Gobernador se debía encontrar otro, que se asegurara de que fuera apto (recibiendo estipendio diario), no superando estas gestiones el coste de 4 doblones, que no se le darían hasta verificarse tal paso. Mientras tanto, debía ir a Oviedo el regidor Antonio García de Tineo como comisario al paso de los once soldados de la villa, «a cuyo cargo a de estar el disponer se hagan las esposas para llevar dichos soldados y también el nombrar las guardas necesarias para el seguro de ellos» ${ }^{21}$. El 31 se lee una orden del Gobernador donde se comunica que la leva ha de ser únicamente de voluntarios, dejando libres a aquellos apresados susceptibles de ser insertos en filas, lo que agrava el problema a la villa y le llevará a intentar formar una compañía propia, como veremos.

Así pasan los días y el 11 de abril el Ayuntamiento necesita saber ciertamente cuántos mozos solteros hay aptos para el servicio en cada parroquia del concejo, nombrando para tal asunto dos o tres delegados de cada una «de los de más inteligencia», los que debían informar en un plazo de cuatro días. Pero la cuestión no cesó, pues el 19 se deben volver a despachar las órdenes enviadas a vistas de que termina el plazo para hacer el sorteo de los once soldados que debía enviar a Oviedo, faltando más de la mitad de los lugares del concejo por traer sus

19 Vid. Martínez-Radío, 2008b: 127- 166.

20 AMGj., Libro de Acuerdos de 1703, f. 15 r.

21 También que dejen suelto a uno de los soldados presos por ser de Gozón. Ibíd., ff. 12 r. y ss. 
delegados con las listas de los mozos, como tampoco estaba la de los hijos de los vecinos ${ }^{22}$. El tiempo apremia, pero la villa tendrá un poco de resuello cuando el 1 de mayo se lee una orden del gobernador dando cuenta de lo acordado en la Diputación en Oviedo sobre los 800 soldados que pedía el rey a Asturias en esos días. Por esa orden se suspendía el sorteo que se había mandado disponiendo luego poner banderas para enganchar voluntarios, siendo este medio más suave y mejor «por considerarse más decoroso a la nobleza de este Principado». A los que se presentaran voluntarios había que comunicarles que se les trataría correctamente ${ }^{23}$, ya que los oficiales que llevaran la recluta serán asturianos y nobles ${ }^{24}$. Serían alojados en los límites de la región y de Galicia para que, en caso de que hubiera una invasión, pudieran servir en una $\mathrm{u}$ otra parte ${ }^{25}$. Esta es una noticia realmente importante para Asturias, porque es el inicio de las gestiones para la creación del Tercio, que tendrá que completar en los años sucesivos. No obstante, Gregorio Jovellanos opina que se debía continuar formando la compañía de soldados propia que estaba creando y a la par intentar cumplir en lo posible con la nueva orden, lo que supone dos reclutas paralelas. Se escuchó y aceptó su propuesta mientras se pondrían las banderas de enganche para cumplir ${ }^{26}$.

En junio crece la tensión cuando el día 21 se lee una orden del gobernador por la que informa que el rey no había aceptado el servicio del Tercio, así que se debía llevar a cabo la leva del $1 \%$ del estado llano (ordenada previamente a aquella nueva oferta), fueran voluntarios o no pero españoles. Así que había que revisar los últimos padrones y remitir a Oviedo en ocho días los soldados levados. De este modo, y a propuesta nuevamente del capitán Gregorio Jovellanos, se debían sacar los padrones y elaborar la lista de los pecheros, que posteriormente revisaría el juez del estado llano, comprobando los fallecidos y los que se habían casado. Una vez hecho esto, se confeccionaría la lista de los sorteables exceptuando al gremio de mareantes. Ya sorteados, el juez de Gijón debía nombrar dos delegados para comprobar si eran aptos según las órdenes recibidas ${ }^{27}$. Es decir, una gran molestia para la villa. La cuestión marca un nuevo giro a mediados de julio, cuando se comunica la aceptación del Tercio por parte del Rey y que Gijón debía enviar delegados para elegir su oficialidad ${ }^{28}$. A partir de este momento la villa, como el resto de Asturias, está ligada en materia de levas a tal nueva unidad, colaborando con sus molestas contribuciones.

Transcurren los meses sin mayor novedad en este sentido hasta casi un año después. Como ya apuntamos, se debía continuar con la política de levas, incorporando incluso hidalgos ante la necesidad de mozos aptos - lo que era considerado una afrenta a este grupo social, pues significaba nada menos que forzarlos-. Pero en ese momento se libran al suspender las levas al haber efectivos suficientes, tanto españoles como franceses. No obstante, se respetaría a aquel que se hubiera presentado voluntario ${ }^{29}$. Obviamente la noticia tuvo que sentirse como un gran alivio. Y no hay mayor novedad hasta finales de octubre de 1705, cuando se le ordena a Gijón que aporte diez soldados al ahora Regimiento de Asturias ${ }^{30}$. En esos momentos la villa

22 Ibid., ff. 33 v., 38v. y 39 r.

23 «[C]on la mayor suavidad y atención que posible sea».

4 «[H]an de ser nativos y de los de primera estimación de este Principado».

5 Ibid., ff. 40 v. y $41 \mathrm{r}$.

26 No obstante, el problema preocupaba a los regidores. Es así como Gaspar Jove Bernardo dijo que el cumplimiento de esta orden no podía perjudicar a Gijón, por lo que los procuradores de la villa deberían dirigirse a la Junta General, «porque siempre es el ánimo del que dice dejar a esta villa en la libertad que tienen para conceder servicios a Su Majestad sin que lo haga por ella quien no puede». Ibíd., ff. 41 r.- 42 r.

27 Ibid., ff. 53 v.- 55 r.

28 Sesión de 17 de julio. Ibíd., ff. 71 v.- 72 v.

29 AMGj, Libro de Acuerdos de 1704, sesión de 23 de mayo, f. 26 r.

30 Se había decretado una leva por la que se solicitaban a Asturias 300 hombres. 
muestra otra vez dificultades para cumplir con la política de levas. De hecho había llevado a Oviedo cuatro voluntarios y solo habían pasado dos; se le habían rechazado tres -dos por tener asentada plaza supernumeraria y el otro por expósito de la ciudad de Oviedo, aunque vecino de Gijón, cuestiones que serán protestadas por los capitulares-, el resto fueron rechazados por no dar la talla o no ser aptos. La villa se ve desesperada para completar el cupo. No le gustó nada que fueran rechazados los hombres que había enviado, con lo que Gregorio Jovellanos incluso solicitó recurrir al propio monarca si fuera necesario. Respecto a los mozos, el temor a servir era más que evidente, pues como es lógico, se trataba de ir a la guerra, con lo que muchos se escapaban y con ello se retardaba el cumplir con el servicio. Lo evidencia claramente el regidor Antonio Espriella Jove:

... suponiendo estar por otras partes obligados y con efecto por estas causas no está cumplido y ahora estar todo el concejo y toda la república tan escandalizada que andan por los montes según se dice, por cuyo escándalo se retarda el real servicio de Su Majestad ${ }^{31}$.

El problema de no cumplir a tiempo eran las sanciones en que podía derivar. El 31 de octubre le faltaban cuatro soldados y, de no ponerlos, debía afrontar una multa de 500 ducados, más los gastos del retardo que le costaba la leva. El regidor Bernardo Antonio de Llanos Cifuentes propone incentivar voluntarios para sacarla del aprieto proveyéndoles de un uniforme lustroso ${ }^{32}$. Felipe la Sala Valdés apoya su postura, que se comunicaría mediante edicto, sumándole «alguna asistencia para que más fácilmente se muevan ${ }^{33}$. Es decir, un incentivo en ropa y dinero (que enlaza con el honor militar y noble). De hecho se buscó por orden del juez ordinario de Gijón, Pedro Oliveros Hevia, movilizar a los nobles oriundos de la villa para servir en el Regimiento mediante un edicto y que, de este modo, se completara el número de hombres solicitados. Y se presentaron cinco hasta el 1 de noviembre ${ }^{34}$, con lo que el problema parecía resuelto. Obviamente, la villa estaba aliviada y muy agradecida a estos voluntarios mostrándolo con palabras de honra y agradecimiento, esperando incluso que cundiera el ejemplo en la nobleza local. Lo deja claro Pedro de Oliveros ${ }^{35}$ :

[S]iendo esta determinación tan gloriosa, parece a su merced debe esta villa explicar su agradecimiento en la manera que debiere y pudiere, pues de esta forma no solamente se remunera la referida determinación, sí también será motivo para que otros se alienten y redondear esta acción y el número que tocó a esta dicha villa y concejo.

El Ayuntamiento en conjunto está tan aliviado que a esa propuesta suma que puedan elegir hasta el color de sus atuendos, se les conceda una compensación económica y se cubran los gastos de su desplazamiento hasta su lugar de destino, nada menos. Obviamente esto nos revela la real necesidad, desesperación y suspiro:

[T]ienen [los miembros del Ayuntamiento] por tan plausible y del mayor aprecio la acción de los hijos de vecino que han asentado plaza de voluntarios y se expresan en la proposición de su merced, que explicando a un mismo tiempo en ella las honradas obligaciones con que nacie-

31 AMGj, Libro de Acuerdos de 1705, sesión de 28 de octubre, ff. 78 v.- 82 r.

32 «[S]olicitar que algunos hijos de esta república procurasen librarla de el conflicto en que se haya sentando plaza de soldados, y que de este Ayuntamiento, atendiendo a su buen celo y cariño, les asistiría con una gala a cada uno para que fuesen con todo lucimiento».

33 Ibid., ff. 82 v.- 83 v.

34 Eran estos Antonio de Hevia Bernardo, Gregorio de Carrio Mirán (quizás sea yerro y deba decir Miranda), Juan Antonio Álvarez Jove, Bernardo de Hevia y Pedro de Nanclares y Gamboa, todos nobles y de Gijón.

35 Sesión de 2 de noviembre. 
ron y el amor que manifiestan a su Patria, mayormente en ocasión de considerarla en tan sumo aprieto y dificultad de cumplir con la obligación de el servicio de Su Majestad, cumpliendo de su Real Orden, que no puede menos esta villa que darles repetidas gracias en común y en particular de que tan generosamente la procuren desempeñar y al mismo tiempo aplicarse cuanto en sus medios le fuere posible a que los referidos vayan a servir con la decencia que compete a su calidad [elites], acordando como desde luego acuerdan se les pague a cada uno una gala [...] y sea la elección del color la que eligieren los mismos señores soldados. Y además de eso se les asista con algún socorro a cada uno para cuando hayan de marchar, y para entonces se les prevengan bagajes por cuenta de ésta conducirlos al Ejército o paraje donde fueren destinados ${ }^{36}$.

Aparte de ello, se acuerda escribir al nuevo Presidente del Consejo de Castilla, Francisco Ronquillo, y al coronel del Regimiento del Principado, Álvaro Navia Osorio para que recibieran trato especial por ser nobles y voluntarios, se les otorgara el grado de cadetes y se distinguieran del resto. Afortunadamente para el consistorio se siguen presentando voluntarios de buen porte en los días sucesivos, suponemos que ante ese trato de especial favor ${ }^{37}$. De este modo, ya el 17 de diciembre, se lee una carta de Navia Osorio, en la que expone que «atenderá con especial cariño» a los caballeros soldados que fueron por Gijón, «por haber resuelto acción tan gloriosa de haber asentado voluntariamente plaza de soldados por esta villa y concejo para ayuda de reclutar dicho Regimiento ${ }^{38}$. Las noticias entre estos y la villa no terminan con su simple enganche y conducción a la unidad, pues a finales de enero se da cuenta de una carta de los nueve soldados que están sirviendo por Gijón y su concejo. En ella comunican su llegada a Ciudad Rodrigo (que defenderán con las armas efectivamente a no mucho tardar) «y repiten sus agradecimientos a esta villa expresando procurar desempeñar su obligación en aquel ejercicio en honra y gloria de esta república [Gijón]». Se acordó responderles y que se les comunique que se les continuará favoreciendo ${ }^{39}$.

En suma, Gijón cumple y, en su opinión, de más. Así lo evidencia el 1 de febrero de 1706 considerando que le tocaban más soldados en los repartimientos de los que deberían. El problema radicaba en los repartimientos, hechos por los encabezamientos de millones y no de vecindario. Así, se le da poder a Gaspar Jove Bernardo y al procurador general de la villa para que se lo comuniquen al rey ${ }^{40}$. Todavía no es consciente de que ese año no es para mucha protesta.

\subsection{EL PROYECTO DE UNA COMPAÑÍA GIJONESA DE VOLUNTARIOS}

1703 es un año de gran tensión y desconfianza. De hecho, a las operaciones militares aliadas en la Península se suma el recelo hacia el que será ya abiertamente el incómodo enemigo Portugal, muy cercano ${ }^{41}$. Todo ello conlleva el decreto de nuevas levas en España, derivando en Asturias en la creación de un nuevo Tercio. Así, buscando el mayor número de soldados

36 Ibid., ff. 83 v.- 86 r.

37 El 9 de noviembre tenemos noticias de que se presentan Nicolás Antonio de Pis Jove, Andrés Mz. Valdés, Francisco Morán Llanos y Antonio Pérez de la Espilla. Ibíd., ff. 87 v. y 88 r.

38 Ibid., f. 99 r.

39 AMGj, Libro de Acuerdos de 1706, sesión de 28 de enero, f. 4 r.

40 Ibid., ff. 5 v. y ss.

41 De hecho, en la villa tuvo lugar un conflicto diplomático entre los meses de marzo y junio al haber sido retenido de forma irregular en el puerto un barco mercante portugués con dirección a Hamburgo. En la correspondencia originada se detecta claramente un ambiente de desconfianza española ante los lusos así como diversos roces con ellos previos a la declaración de guerra. NA, State Paper Office, 89/25, doc. 47, ff. 138 r.-143 r.; AHA, Notariado de Asturias, Distrito de Gijón, caja 1.896/6, ff. 46 r.-48 v. (es de agradecer la ayuda de Ángel Argüelles, del AHA, en esta última referencia). Recogido el caso en Martínez-Radío, 2018: 10. 
(aparte de tal unidad), finalizando marzo, el gobernador del Principado comunica que la leva que se estaba efectuando no fuera de forzados, sino de voluntarios ${ }^{42}$. El problema, como vimos, es encontrarlos, como dejó claramente expuesto el capitán Gregorio Jovellanos a comienzos del mes siguiente ${ }^{43}$. A su iniciativa la villa intentará formar una compañía propia, con un mínimo de 40 hombres. Esta daría ejemplo y animaría a otros a alistarse en ella ${ }^{44}$. Propuso así que se tratara de buscar el número suficiente para ofrecerla al servicio del Rey, cargando el Ayuntamiento con los costes derivados a cambio de que la Corona concediera las patentes de oficiales $^{45}$. Con ello, que se nombraran encargados para gestionar el que sentaran plaza todos los hijos de vecinos de la villa y el concejo y que cumplieran con su deber innato y el honor de servir a su Rey y Patria en la compañía ${ }^{46}$. Si no hubiera suficientes hombres (cuestión que se sabría en 8 días), tales encargados deberían alentar a los vecinos para cumplir con las órdenes reales. Si el rey concediera las patentes de los mandos, los que la formaran podrían reelegir y nombrar sus oficiales, siempre que fueran de la calidad y oriundos de la villa o concejo. Así se acordó y ya acuden el mismo día nueve voluntarios ${ }^{47}$ con la condición de que se respetaran las propuestas estipuladas para tal unidad. Al siguiente, llegan otros aludiendo explícitamente a formar parte de una compañía de soldados «de superior calidad» que les ofrece la posibilidad de «reconocer el lustre y graduación de gran séquito que de eso se les sigue». Es decir, de la elite local. La idea no fue mal acogida si nos atenemos a los presentados en un primer momento, la mayoría residentes en la villa, conllevando entonces dos reclutas paralelas: la leva general y esta recluta particular ${ }^{48}$. Incluso se presentaron hombres de otros concejos, debiendo acordarse el día 11 que, respecto a que no tenían donde albergarse ni qué comer, se les buscara «posada decente y modo de alimentarse». Al siguiente se acuerda dar a cada soldado de la compañía 3 reales de vellón diarios. Comenzando mayo y ante el llamamiento general de voluntarios en Asturias, como ya apuntamos, Gregorio Jovellanos expone la conveniencia de no abandonar la idea de esta unidad. Esto es porque, si la villa la tuviera completa, podría servir con ella como había acordado y, llegado el caso, se entendería con el Principado sirviendo con esos oficiales y soldados. De no conseguirse, podría hacer lo que considerara más conveniente y no se le culparía «de a que, habiendo una vez acordado y puéstolo por obra, se deja experimentar el último remedio». Por ello y en esa leva paralela, si algún soldado alistado necesitara

42 AMGj, Libro de Acuerdos de 1703, ff. 9 r. y 19 v.

43 Sesiones de 31 de marzo y 2 de abril. «[P]ues, habiéndose echo a muchos de los que se hayan en disposición de ir a servir la proposición de que lo hagan, se hayan muy tibios».

44 «[F]ormándose una compañía por esta villa y su concejo del número por lo menos de hasta cuarenta, se podrán alentar a asentar plaza en ella». Al parecer dos oriundos de la villa habían comunicado que, en caso de formarse tal compañía y se les concediera la condición de oficial, ellos se alistarían y animarían a otros a seguirles.

45 Los costes de la creación de una unidad eran onerosos. Para este caso concreto, también sugiere solicitar que la Corona le conceda a la villa el dinero «del arbitrio más conveniente y que pareciere menos gravoso». Ibíd., ff. 20 r.-21 r.

46 «[P]ues esta república no puede hacer más por sus hijos, ni ellos por su Patria, que ponerlos en la buena disposición de que cumplan tan noblemente con las obligaciones con que nacieron de tal en el servicio de su Rey en la ocasión que Su Majestad, por tan repetidas órdenes, vayan asistir a su real persona en la determinación que tiene de salir a esta próxima compañía». Ibíd., ff. 21 r. y 21 v.

47 Francisco Díaz Veanes, Francisco Morán Llano (menor de edad), Nicolás de Pis Jove, Pedro Nanclares Gamboa, Felipe de Carrio Miranda, Antonio Morán Lavandera (más adelante el que parece su hermano), Bernardo de Hevia, Bartolomé de la Espilla, Gabriel de Llanos Cifuentes. Al día siguiente, Francisco de Valdés, Gregorio de Carrio Miranda y Antonio Moris Jove. Al otro, Gregorio Suárez Puago, José García Argüelles, Justo Fierros Valdés (a quien se le da un trato de excelentísimo) y Francisco Mieres Estrada. Ibid., ff. 23 v. y 27 r.

48 El día 5 se presentan voluntarios Rodrigo Fernández Solís, Pedro Palacio Argüelles, Cosme Blanco de Valdés, José Antonio Menéndez Jove y Valdés, Francisco Fernández Miranda (éste último no sabe escribir, el resto sí), Juan Fernández de Jarva Somonte Poago; el 10 se presenta Toribio Ladreda (no lo firma por no saber); el 11 José Suero Díaz Balbín y Antonio García la Villa; el 14 Francisco Morán Lavandera y uno que ya había sentado plaza de soldado y ahora lo vuelve a hacer para la compañía de Gijón. Ibíd., ff. 26 v.- 28 v., 34 r., 34 v. y 37 v. 
el sueldo o parte de él, se le debía pagar. No obstante y finalmente, a pesar de los incentivos, en junio es evidente que la compañía no había conseguido reunir todos los soldados necesarios, a lo que se sumó que la Corona no aceptó el servicio con la condición de que nombrara sus oficiales y, de este modo, se disuelve. Lo que sí se debía llevar a cabo era la leva decretada en el momento del $1 \%$ del estado llano ${ }^{49}$. La cuestión ante tal propuesta es llegar a discernir si se trataba realmente de cumplir con la Corona o, ante los inconvenientes que conllevaba, estamos ante una estratagema para cumplir sin mayores molestias.

\section{1706. REACTIVACIÓN DE LAS MEDIDAS}

Realmente las noticias de alarma de la villa se diluyen en este tiempo, siendo las pocas de relevancia aquellas concernientes a completar el Regimiento del Principado. La situación vuelve a cambiar ante el avance austracista de 1706 que llegó a tomar Madrid. Nuevamente el nerviosismo. De hecho, a mediados de mayo reciben órdenes para tener hechas en quince días nuevas listas de hombres, eso sí, sin dejar despoblados los lugares. Inquietaba el avance portugués y se llama a salir de cada casa y familia a los más aptos, pero no aquellos que debieran mantener a su familia o tuvieran responsabilidades políticas o administrativas ${ }^{50}$. El día 19 se acuerda cumplir con la orden, nombrando el juez los delegados para realizar las listas: el capitán Gregorio Jove Llanos, Gaspar Antonio Jove Bernardo, Felipe de la Sala Valdés y Juan de la Espriella Jove. El primero volverá a hacer notar su espíritu de sacrificio calificando el asunto de «materia de tanta honra (...) alistarse y sacrificarse a su real servicio $»^{51}$ y quedan designados para alistar Gregorio de Jove Llanos, como alférez mayor, Andrés Francisco de Jove Llanos ${ }^{52}$, su hijo, y Carlos de Valdés Hevia y Caso. Los demás comisarios nominarían a los que consideraran más adecuados. Pero lo interesante del caso es que los miembros del Ayuntamiento hacen alarde de gallardía alistándose ellos mismos y a familiares. Gaspar Antonio de Jove Bernardo así lo hace tanto para él como para su único hijo, Baltasar Gregorio Jove Bernardo; Juan de Jove Estrada se ofrece a servir tanto él como sus dos hijos (Francisco Antonio y Antonio de Jove), lamentando «no tener muchos más que dedicar al servicio de Su Majestad»; Juan de Jove Espriella también se ofrece a servir y dice que, como no tiene hijos en edad de tomar las armas, cuando la tengan los alistará a los tres; Felipe de la Sala Valdés hace lo propio, aunque contara con 63 años; los demás capitulares, cumpliendo con dicho real despacho y por el motivo que se les da «de constituirse en la mayor gloria», siguen el ejemplo para ayudar a la Corona en las urgencias de la guerra; el propio juez de Gijón hace lo propio y lamenta no tener muchos hijos para alistarlos. Todos excepto Francisco de Llanos Cifuentes por contar más de 78 años y sufrir achaques notorios. Es decir, antes de hacer las listas por la villa, se apuntan ellos mismos y su familia. No obstante, en julio no había ido ninguno al frente aludiendo a que tenían responsabilidades políticas, así que se acabará forzando a los pecheros. El 5 de julio Gaspar Antonio de Jove Bernardo lo deja claro cuando recuerda el decreto de mayo con la excepción al servicio de aquellos necesarios para llevar la administración y las familias. A pesar de todo, debía haber sensación de peligro, que pesaría debido a las amenazas de la costa mas los progresos aliados por el interior y flotando un temor a perder la guerra en

49 Ibid., ff. 33 v., 37 r., 55 v. y 56 r.

50 «[L]os que se tuvieren por preciso para el gobierno de las repúblicas». AMGj, Libro de Acuerdos de 1706, sesión de 16 de mayo, ff. 51 r. y $51 \mathrm{v}$.

$51 \quad$ Ibid., ff. 52 r. y 52 v.)

52 Debe tratarse de Andrés Jovellanos, alférez mayor de la villa y concejo por privilegio otorgado por Felipe II a su antepasado Francisco Álvarez de Jove en 1558. Pérez de Rada, 1999: 234. 
este momento. De hecho, el mismo día y también Gaspar Antonio Jove Bernardo, da cuenta de la situación de peligro: avance aliado, destacando las fuerzas lusas, precisamente desde Portugal, llevando la iniciativa y dominando Castilla la Vieja, cortando las comunicaciones con la Nueva mientras no había noticias seguras de Felipe $V^{53}$. Por ello, vuelve a hacer un llamamiento a las elites locales a cumplir con honor tomando las armas, dejando excusas aparte:

[P]arece son estos motivos que ejecutan a la honra que heredamos de nuestros mayores a que nosotros mismos dispersemos los inconvenientes referidos y procuremos después de alistados armarnos y hacer el ánimo de sacrificar nuestras vidas por las dos Majestades [Dios y el Rey] y por la Patria, que nos debemos de prometer que ningún noble de esta villa y su jurisdicción no hallará inconveniente para una cosa tan precisa ${ }^{54}$.

De este modo y a su iniciativa, se dio bando público para que aquellos que tuvieran causa justificada para no alistarse la expusieran en el Ayuntamiento o en la casa del juez que presidía la villa. El dicho bando contenía la advertencia de que aquel que no lo hiciera quedaría alistado «y le parará perjuicio». La lista de los mozos se debía remitir al Rey para que dispusiera de ellos donde le pareciera más conveniente. Lo interesante es lo que apuntamos de que finalmente ellos no fueron, pero sí mandan a los pecheros.

Con todo, si bien la alarma descenderá, la guerra continúa y en diciembre el Principado deberá afrontar una nueva recluta de 260 soldados para el Regimiento cargando a la villa, lo que supuso una nueva molestia ${ }^{55}$.

\section{GASTOS POR LAS LEVAS}

El hecho de levar era problemático tanto por sus repercusiones sociales como por gravoso. Los costes de la villa, a no ser por iniciativas propias como vimos, iban asociados a los del resto de Asturias y, sobre todo y como es lógico, a los del Tercio/Regimiento del Principado. Para costear tal unidad, ya en el verano de 1703 se impuso en Asturias un impuesto de 1 maravedí en cuartillo de vino (puchera) ${ }^{56}$.

La llegada de las noticias de tal carga no fue bien recibida, como era de esperar. Gaspar Jove Bernardo lo deja claro cuando expone que con el maravedí en cuartillo se le perjudica, porque rendiría más el impuesto en vino que en otros dos juntos sin tocarle la mitad de soldados que a otro concejo que consumiera mucho menos de esta bebida. Es más, según él, aunque se dijera que a Gijón le ayudaban los forasteros que llegaban por el comercio (lo cual entonces es evidente que tenía importancia incluso en la guerra), debía hacer frente a muchos gastos inevitables y elevados, como obras del muelle, el hacerse con pólvora y pertrechos de guerra o pagas anuales de censos y más cuestiones en las que no le ayudaba ningún otro concejo. Por si fuera poco, ninguno hacía frente a contribuciones como él, así que no debía contribuir por otros. Así pide que se informe al gobernador y se solicite que el Rey le concediera facultad a Gijón para que usara el arbitrio como le pareciera a la villa de manera más conveniente ${ }^{57}$. En

53 Esto último es el motivo por el que él y los demás caballeros nombrados para efectuar la lista no la habían hecho ya que, atendiendo a la orden del presidente de Castilla, solo debían ir los solteros que no fueran hijos únicos de viuda. AMGj, Libro de Acuerdos de 1706, ff. 51 r.- 53 v. y 72 v.

54 Ibíd., ff. 72 v. y 73 r.

55 Ibid., ff. 149 v.- $150 \mathrm{v}$.

56 Se informa sobre este asunto en el Ayuntamiento de 29 de agosto 1703. AMGj., Libro de Acuerdos de 1703, f. 83 v.

57 « $[\mathrm{Y}]$ para que pida que a esta villa se le dé tratado de la facultad de Su Majestad para que por si pueda usar del arbitrio del modo que le pareciere más suave y conveniente». Ibíd., ff. 83 v. y 84 r. 
la misma manera, que se hiciera el repartimiento respecto al número de soldados que le tocara, con lo que así podría aportar el dinero y hombres en el plazo preciso. Gregorio Jovellanos, alférez mayor, apoya su postura añadiendo que se comunicara al gobernador que Gijón no podía contribuir por las razones expresadas. No obstante, obedecerá.

En el Ayuntamiento no hay mayor novedad al respecto hasta mediados de octubre, cuando vemos las primeras cifras reales a afrontar. Le tocan 19792 reales del prorrateo que debe cubrir respecto a un arbitrio de gastos por la guerra ${ }^{58}$. Como vamos viendo, se le suman gastos y va cubriéndolos como puede, más mal que bien, pero el endeudamiento es inevitable. De hecho, el 14 de junio de 1704 dos vecinos de Gijón (por tanto, particulares), Pedro de Condres y Domingo de Hevia, se ofrecen a prestar, como así harán, 3000 reales de vellón para los gastos del Tercio para el primer día de San Juan y 800 para el año siguiente. Poco más de dos meses más tarde, de Hevia, por mano de Condres, pagará en Oviedo 3000 reales de orden de Gijón para ayudar a los gastos que le tocaron por el Tercio, y también darán los 800 como acabamos de mencionar ${ }^{59}$.

Deducimos que el asunto se podría considerar ya más o menos grave hasta el año siguiente, cuando contamos con cifras exactas que nos ofrecen una idea clara de los gastos. A mediados de noviembre, Pedro Oliveros Hevia presenta la cuenta de los derivados de nueve soldados que se habían presentado voluntarios hasta que fueron a Oviedo: 1970 reales y 21 maravedís de vellón. En este año le tocó a Gijón aportar diez soldados para el Regimiento, lo que le costó 30750 reales de vellón, pero el maravedí en cuartillo de vino solo había suplido 20800 reales (suponemos que se sean las cuentas totales, desde 1703). Se ve que están endeudados con las cofradías de ánimas, a las que llegarán a deber a fines de noviembre de 1705 más de 6000 reales por el avío de los soldados para formar el Tercio ${ }^{60}$. Estas son las cifras claras que aparecen en la villa como propias, siendo las restantes las asociadas al resto del Principado y de las que ya no hay eco en las actas locales.

Pero, aparte de los gastos propios de una leva (prensión, mantenimiento...), también los había por bajas de deserción. Un ejemplo claro lo vemos el 25 de septiembre de 1706 cuando se da cuenta de que el gobernador estaba en la villa procediendo contra ella y recaudando 69 reales de vellón por los gastos causados por un soldado desertor del Tercio, de nombre Domingo la Medina. El Ayuntamiento necesita quitarse el problema de en medio rápidamente para no sufrir penalización y delega en Juan de la Espriella Jove «para que busque y saque la referida cantidad de don[de] lo tuviere esta villa ${ }^{61}$.

\section{LA PREPARACIÓN Y PERTRECHOS DE LOS MILICIANOS}

Oficialmente, Asturias y con ella Gijón, mostraron clara fidelidad a Felipe V, lo que conllevaba preparase para repeler una agresión. Estanislao Rendueles Llanos destaca la posición de

\footnotetext{
58 Asturias, y con ella Gijón, hubo de contribuir en diversos gastos, desde las medidas de fortificación hasta la manutención de prisioneros. Para costearlos se endeudó e impuso arbitrios o censos. Por ejemplo, en noviembre de 1704 se manda que Gijón retenga la tercera parte de los réditos de los censos fundados sobre sus propios y rentas, la cual iría destinada a la recuperación de Gibraltar y Ceuta. AMGj, Libro de Acuerdos de 1704, f. 106 r. El censo más notorio y que sirvió para diversos gastos fue el contraído con el marqués de Tolosa, Miguel Fernández Durán, que se prolonga cuatro décadas, hasta febrero de 1756. Para una visión global del mismo, Vid. Martínez-Radío, 2013: 46-50. Del mismo autor, 2009: 292-296 y 322-325.

59 AMGj, Libro de Acuerdos de 1704, ff. 40 r. y 40 e ibid., 21 de agosto, f. 66 v.

60 Se ve que están endeudados con las cofradías de ánimas de Gijón, a las que llegará a deber a fines de este mes más de 6.000 reales por avío de soldados para formar el Tercio. AMGj. Libro de Acuerdos de 1705, 16 y 25 de noviembre, ff. 89 v. y ss.

${ }_{61}$ AMGj, Libro de Acuerdos de 1706, f. 124 r.
} 
la villa en decidido amparo del pretendiente Borbón «prodigando en su defensa sus hijos y sus caudales ${ }^{62}$. Con ello, el 8 de julio de 1706 vemos ya el recuento y limpia de todos los mosquetes, la revisión del estado de la artillería, pólvora, munición y cuerda y las reparaciones necesarias donde hubiera lugar. A la par, se tomó munición y cuatro cañones que había en la zona del Natahoyo. En lo que hace a las armas portátiles, la tarea está terminada el 19 de agosto ${ }^{63}$.

Obviamente, en el factor humano hay dos aspectos importantes a tener en cuenta. El primero es el número de hombres, su moral y habilidad para el combate. Por otro lado, que cuenten con los medios adecuados para ello y, cuanto mejores sean, mejor capacidad de lucha tendrán los hombres, tanto por los propios medios como en la medida en que estos puedan afectar a su moral al sentirse más o menos seguros o capaces. Así, no bastaba con que hubiera milicianos en número suficiente, sino que además debían ser capaces para usar las armas, para lo que se precisaba un mínimo de adiestramiento de cara a ser eficaces. Por esos días el capitán Pedro de Valdés incide en el carácter de indefensión de la provincia, destacando el caso gijonés. De ahí que destaque la importancia de la disciplina y adiestramiento de los milicianos, recomendando al capitán de Infantería José Cuervo (con lo que debían conocerse previamente), quien es enviado a la villa para su instrucción. Este capitán ya estará en tal tarea el 27 de julio, acompañado del teniente coronel Francisco Bernardo de Quirós ${ }^{64}$.

Seguirá Pedro de Valdés recordando al gobierno del Principado sus temores mientras busca pertrechos. Con ello trataba de que le facilitaran medios y contará con el apoyo del Ayuntamiento, que acordó el día 11 de julio tomar la pólvora necesaria, cifrada en 10 quintales, así como la munición, artillería, mosquetes y cuerda, sea por préstamo, endeudándose o requisándolo. Los encargados del recuento de mosquetes y munición serán los regidores Bernardo Antonio de Llanos Cifuentes y Juan de la Espriella Jove ${ }^{65}$, mientas se requisa toda la pólvora que tuvieran los mercaderes de Gijón ${ }^{66}$. Dos días más tarde, Pedro de Valdés comunicó que el gobierno del Principado había escuchado los argumentos de la villa y acordado conseguir 60 quintales de pólvora (en general), mosquetería con su cuerda y munición de esta y de artillería ${ }^{67}$, así como había obtenido permiso para hacerse con los cañones de un barco que había naufragado en la concha de Cudillero, de nombre San Cayetano (lo cual se traduce en más gastos) ${ }^{68}$.

Poco más de una semana después, Fernando de León Falcón comunica que, ante los avances enemigos, el Gobernador y él habían decidido que se debían tomar las medidas oportunas para proteger los puertos de mar ante posibles agresiones. Como Gijón era la villa más ex-

62 Rendueles Llanos, 1867: 303 y 313. Se centra más en los primeros momentos del conflicto y los sucesos de 1703, para dar paso después al final del mismo (pp. 313-317). En lo referente a la fidelidad asturiana al Borbón, está tratada en Martínez-Radío, 2005. En el Ayuntamiento de Gijón el 11 de julio de 1706, unido a los reveses militares borbónicos, con las noticias de que el Principado había acordado que don Francisco Bernardo de Quirós, teniente coronel, y don Carlos Ramírez de Jove partieran a mostrar su fidelidad al Borbón «como fieles y leales vasallos, sacrificando sus vidas y haciendas en la defensa de su rey y señor don Felipe Quinto (que Dios guarde) y de su Patria». AMGj. Libro de Acuerdos de 1706, ff. 78 v. y 79 r.

63 Ibid., f. $78 \mathrm{r}$.

64 Ibíd., ff. 79 r., 79 v. y 94 v.

65 Quienes además debían disponer la fabricación de cureñas donde fuera necesario.

66 Ibid., ff. 79 v.- 80 v.

67 Para costearlo se utilizaría dinero de la Corona, pero en caso de no poder ser así, se planteó un repartimiento entre todos los concejos asturianos. Gijón debía 3000 reales a la duquesa del Infantado por política económica general asturiana, dinero que le entregó a José de Toro Escajadillo, vecino y regidor de Oviedo y Depositario General del Principado. La villa había acordado el día 11 que ese dinero se utilizara en este menester, quedando a deber otra vez entonces a la duquesa y endeudándose de nuevo, pero resulta que José de Toro le dio esa suma para lo que ahora pretende-sin solicitarlo, e incluso más proveniente de donaciones voluntarias y de sí mismo-.

68 Según memorial de Bernardo Antonio de Llanos Cifuentes presentado el 20 de diciembre, la villa hubo de afrontar un gasto de 1164 reales y medio de vellón por tal empresa, así como otras medidas de habilitación de artillería. Ibíd., ff. 81 r., 81 v. y 151 r.- 152 r. 
puesta, necesitaba mayores prevenciones mejorándose el artillado y construcciones defensivas. Así, aparte de la nueva construcción del fortín tras la iglesia parroquial, se deben llevar a cabo mejoras en los baluartes de Arnao, Torres, Somió y Coroña, a realizar por los milicianos de cada lugar, ahorrando así gastos de propios $^{69}$. En lo que respecta a los pertrechos para los hombres movilizables, había 15 o 16 quintales de pólvora, que podría ser suficiente tanto para el uso de la artillería como para el de los vecinos, aunque probablemente habría que redistribuirla. Pero, por el contrario, se precisaba de cierta munición, así de artillería como de arcabucería, y cuerda.

A pesar de que a mediados de agosto llegan a la villa buenas noticias de armas a la causa borbónica, incitando a su celebración, la guerra distaba de terminar, por lo que el Gobernador solicita un donativo para las causas del monarca. En seis días aparecen 341 donantes (pero no son todos, pues también los hubo reticentes y la cuestión se alargó hasta diciembre) ${ }^{70}$, entre los que hubo regidores y notables -con más posibilidades- dando ejemplo con cantidades variables. Entre ellos, don Alonso Solares Valdés, administrador general de las salinas del Principado y regidor de la villa de Villaviciosa, con 16 escudos de plata, o el propio capitán Pedro de Valdés, con 2 doblones que pagó al contado (no todos los hicieron así). Se aportaron un total de 8260 reales y 14 maravedís de vellón ${ }^{71}$.

La villa hubo de afrontar otras cargas esos días unidas a las de la región. Por ejemplo, contribuir con un donativo de 1200 doblones para gastos de guerra a costear con un nuevo arbitrio de 2 reales en fanega de sal o un donativo en 1710 de 700 doblones más 300 que proporcionará la ciudad de Oviedo, todos con sus problemas de cómo poder sufragarlos ${ }^{72}$. Recordemos el contexto de una tierra pobre pero que debe colaborar con mayor o menor convicción, dejando de lado sus pretendidas foralidades ${ }^{73}$.

\section{LAS LISTAS DE MILICIANOS DE 1710}

Las noticias sobre el conflicto van difuminándose en cantidad y gravedad hasta septiembre de 1710 con una Real Orden de Juan de Elizondo sobre cómo actuar con las milicias del Principado $^{74}$. El contexto es de zozobra en el partido Borbón, pues sus enemigos habían entrado en Madrid por segunda vez, con lo que se podría sospechar el fin de la contienda. Pero no fue así, pues Felipe $\mathrm{V}$ estaba en la tarea de reorganización y de retomar el terreno perdido, por lo que dispuso que todas las milicias de España estuvieran preparadas para entrar en acción y hacer recuento de sus efectivos para tomar las disposiciones más convenientes, incluyendo las asturianas.

Seguramente sea que, a raíz de ello y de la importancia de Gijón, veamos en la villa las listas más completas de milicianos que encontramos en Asturias. Así es, pues el gobernador,

6922 de julio. Ibíd., ff. 82 v. y ss.; AAGHA, Fondos del Archivo Revillagigedo, Casa de Valdés, carpeta 160, doc. cit., ff. 1 r.- 3 r.

70 Cierto es que tal donativo sería voluntario, pero dudamos realmente de ello, ya que el juez mandó que los porteros (Pedro y Nicolás Fernández Sopeña) convocaran por la tarde del día 19 a los capitulares al Ayuntamiento a cumplir con el mismo, bajo pena de 2 ducados.

71 AMGj., Libro de Acuerdos de 1706, ff. 103 r.-105 r., 106 r.-109 r. y 153 r.

72 Vid. ibíd., ff. 248 r.- 249 v. AHA, Actas Históricas de la Junta..., t. X (5 de agosto de 1707- 30 de septiembre de 1712), f. $55 \mathrm{v}$

73 AHA, Actas Históricas de la Junta..., t. IX (21 de mayo de 1704- 4 de abril de 1707), ff. 207 v., 208 r., 234 r., 234 v. y 239 v. AMO, Libro de Acuerdos de 1710, ff. 115 v., 120 r., 120 v., 125 v. y 127 v.; año de 1711, f. 3 v.

74 AHA, libro de signatura 6, reseña «Cartas-órdenes, Cédulas e Instrucciones de S. M. relativas a levas, reunión de desertores y sobre milicias con dos Ordenanzas para éstas», f. 102 r. 
Gonzalo Cegrí, ordena en noviembre al capitán Pedro Miguel de Valdés Miranda que le proporcione una completa. Qué datos nos ofrece la nueva información que se origina:

a) Sobre las armas base de los milicianos:

- Serían tres: fusil, arcabuz o lanza ${ }^{75}$.

- Se evidencia la relevancia del arma de fuego, incluso por aquellas personas provenientes del común. Así, tanto en una primera de noviembre, como en la última lista formada por hombres de extracto llano, son un 100\% (arcabuces) ${ }^{76}$.

- Había en la villa 190 vecinos movilizables, de los que nueve no disponían de ningu$\mathrm{na}^{77}$, con lo que se las debía proporcionar el Ayuntamiento. Por tanto, cada uno debía mantener la suya propia.

b) Desde el punto de vista organizativo y social:

- Una compañía sería de unos 80 hombres, no 100 como habíamos visto.

- Distinción entre solteros y casados. Esta medida seguramente respondiera a las necesidades de movilización en un momento dado según urgencia.

- El gremio de mareantes, en el que estaba incluido el artillero de la villa, era igualmente tenido en cuenta por el capitán, quien debía disponer sobre él.

- En las primeras listas aparecen muchos regidores y nobles. En este sentido, sospechamos que la villa pudiera conocer bien quiénes eran sus milicianos, entre los que estaban incluidas sus elites, al menos en teoría. En el mismo sentido, y más tras las palabras de sacrificio vistas más atrás, pudiera llevarnos a pensar que estuvieran interesadas en desempeñar una función honrosa, más si se trata de nobles cuyo essere naturale originario serían las armas, unas elites susceptibles de ser movilizadas. Evidentemente, enlaza con que contarían con más medios para mantener armas de fuego. Sin embargo, hay una carta reveladora a fecha de 15 de diciembre al capitán Pedro Valdés por pluma del sargento mayor Fernando de León Falcón, en la que expone que había pasado a darle las listas al gobernador e intentado que se excluyeran a los regidores, sin quedar exentos los nobles al no distinguirse del

75 Lo decimos porque en ellas figuran al lado de cada miliciano las letras A, F o L. Deducimos que aquellos provistos de arcabuz se les marque en las listas con la letra A; los provistos de fusil con la F y, por supuesto, la letra L pudiera referirse a una lanza o chuzo. AAGHA: Casa de Valdés, leg. 20, carpetillas 72 y 73.

76 No obstante, es en esas listas. De las elaboradas por el capitán destacamos, precisamente, dos de 13 de noviembre. Es en la primera donde figuran 80 arcabuceros, todos de la «primera calidad y nobleza» de la villa, que quedarían alistados. La segunda es la más amplia, mostrando 190 aptos por edad susceptibles de ser movilizados si hubiera que ampliar los efectivos y donde no hay sólo arcabuces o fusiles. Consta de 501 hombres con sus armas, que serían 426 : 356 arcabuces, 59 lanzas y 11 fusiles (sin incluir dos fallecidos que también se referencian), aparte del capitán, 5 sargentos y 5 cabos, incluyendo regidores, solteros y los pertenecientes al gremio de mar. Aquí no consta el arma a 72 hombres, incluyendo los 47 especificados como solteros. Igualmente, hay uno que podría portar tanto arcabuz como chuzo, otro no especificado y el artillero de la villa. Así, de las armas que se especifican, las de fuego constituirían poco más de un $86 \%$ y las blancas cerca de un 14\% del total. De éstas, 137 arcabuces y 6 lanzas serían del gremio de mareantes, lo que supone casi un 33,57\% del conjunto (y respectivamente un 37,33\% de las de fuego y un 10,17\% de las blancas). Nótese que no figura ningún fusil. Destacamos también la lista de 18 de diciembre, con 70 arcabuceros (desestimada por el gobernador), y la de 28 de diciembre, con 80 hombres provenientes de capas populares. En ésta aparecen todos significados con una $A$, lo que nos indicaría un arcabuz, a pesar de no contar con armas de fuego en principio, con lo que es de suponer que fueran facilitadas por el Ayuntamiento.

77 A saber: Bernardo Palacio, Francisco López Franchón, Luis Rodríguez, Bartolomé Sopeña, Medero la Piñera, Juan de Quirós, Pedro Pérez, Antonio Morán y Juan del Puerto. Sin embargo en la segunda lista de 13 de noviembre y en la de 28 de diciembre aparecen armados, dándose una mejora en alguno de ellos, pues cinco contarían en principio con una lanza o chuzo y en diciembre todos figuran con arcabuz. 
común -obviamente se trataría de baja nobleza $-{ }^{78}$. Así, Gonzalo Cegrí le ordena al capitán que realizara unas nuevas ${ }^{79}$ y Pedro Valdés ${ }^{80}$ debe llevar a cabo la tarea rápidamente. Redactó varias entre el 13 de noviembre y el 28 de diciembre, siendo rechazadas por el gobernador al menos en dos ocasiones ${ }^{81}$. Este hecho evidencia que no fue tarea fácil y hubo de tomarse el asunto en serio. Entonces hubo improvisación en realizarlas, lo que nos lleva a dudar de que hubiera una fija. Respecto al alistamiento final de nobles, la diferencia entre las primeras de noviembre, incluyendo los hombres susceptibles de ser alistados, y la última de diciembre, ya restricta exclusivamente a la compañía de la villa, es evidente, pues en esta se especifica claramente que no, comprendiendo únicamente hombres del común y oficios como sastres o carpinteros, así como pobres a los que habría que pertrechar ${ }^{82}$.

Según avance el conflicto hasta su final y la fortuna va sonriendo a Felipe V, Gijón va perdiendo temor a la par que ganando confianza. De hecho, a mediados de octubre de 1712 ya debe dar por terminada la contienda, pues Andrés García Argüelles se queja en Junta General de los agravios que, según el concejo, había sufrido la villa durante la misma, tanto en dinero como en hombres ${ }^{83}$.

Pero las relaciones entre Felipe V y Carlos VI distanciaban de ser buenas y realmente, tras duros conflictos por dos décadas, no habrá paz entre ellos hasta 1725, cuando a comienzos de junio se da cuenta de los ecos del Tratado de Viena. A pesar de la situación económica del momento, se dispone celebrar el hecho disparando salvas, repicar campanas, encender una docena de barricas (seguramente de saín) y poner iluminarias, penando con 2 ducados al vecino que no cumpliera. También, en acción de gracias y para que «su Divina Majestad mantenga la paz universal» y conceda buen tiempo, se celebre en la única parroquia de la villa una misa cantada solemne, con asistencia de dieciocho sacerdotes y religiosos ${ }^{84}$.

\section{CONCLUSIONES}

A pesar de los antecedentes de las épocas anteriores, parece que el temor no había calado realmente en la villa hasta que efectivamente se da cuenta de los desembarcos aliados en Andalucía en 1702 y la presencia enemiga en la costa. En ese momento cunde una inquietud que hará que se vuelque en mejorar su situación defensiva, siendo los años más críticos los de 1703, 1706 y 1710, este último un momento realmente importante de puesta en día de sus compañías de milicias. Sin embargo, una vez que el conflicto da lugar a la calma aunque no hubiera finalizado, cambia su actitud de temerosa y solicitando ayuda a una de protesta por estar sobrecargada en contribuciones, cambio dado entre 1710, momento de la citada puesta en día de las compañías, y 1712, año de la queja de Andrés García Argüelles en Junta General.

\footnotetext{
78 Así que no se distinguiría del pueblo llano ni por lustre ni por ocupaciones.

79 Ibíd., carpetilla 72.

80 También figura el sargento mayor, aunque no en la última.

81 Aparte del rechazo que hizo a las mismas a mediados de mes de diciembre, ordena hacer otras el día 26. Nos constan una sin fechar, las dos aludidas del 13 de noviembre, otra de 18 de diciembre y la última mencionada de 28 de tal mes.

82 «[T] odos ellos... tienen oficios de sastres, carpinteros, canteros y zapateros y los más pobres que no tienen armas de fuego ni con qué municionarlas», Ibíd.

83 Recogido en Martínez-Radío, 2009: 182.

84 AMGj, Libro de Acuerdos de 1725, ff. 5 v. y ss.
} 
Respecto a la indefensión del Principado expuesta en el memorial al Rey de 1703, realmente no se le atendió como esperaba, seguramente porque no se veía como un objetivo mi$\operatorname{litar}^{85}$. En el caso de que hubieran aquellas 132 compañías de milicias, somos recelosos ante el lamento de Gijón exponiendo su vulnerabilidad y que podría caer con menos de 2000 hombres, ya que de ser cierto que había 13200 milicianos en Asturias (cosa que tampoco podemos aseverar) sería un temor relativo en tanto no se haría esperar una respuesta y en el peor de los casos lograrían ganar tiempo hasta contar con apoyo de Castilla o Galicia ${ }^{86}$. Tal cuestión dependería de la calidad de las unidades enemigas, si bien es cierto que entendemos que los milicianos no serían demasiado efectivos ante un enemigo bien preparado y pertrechado. Pero, aparte de las milicias, es de suponer que pudiera haber una resistencia de la propia población local, de modo parecido como sucedió en mayo de 1703 en el puerto de Lastres. Con todo, podemos sospechar que se diera esta cifra tan alta porque es la que esperaría la Corona y para no reconocer el estado real de estos cuerpos defensivos. Aquí, en un contexto de urgencia, en 1710 se evidenció la realidad de que las compañías no sería de 100 hombres, sino de 80 , y suponemos que en el mejor de los casos. Ese año fue cuando se ven las listas claras y completas de quiénes eran los milicianos; hasta el momento los datos eran confusos. Ahora se dan cifras y recuento de sus pertrechos, que debían de mantener -dejando ver la importancia del arma de fuego-, y miembros, que en un principio incluían a las elites locales -constituyendo un cuerpo que otorgaba honor y distinción en la función de la defensa (inherente a la nobleza)-, pero que acaba cargando a pecheros y pobres, eludiendo aquellas elites el compromiso de servir.

En lo que hace a las funciones de las milicias, superaron las meramente defensivas, siendo utilizadas como mano de obra y así una herramienta más barata.

Estamos ante un Gijón que busca cumplir en levas por el perjuicio que le podía suponer, ofreciendo incentivos en dinero, atuendo, consideración... cuando no estaba sobrado de medios. Así se evidencia, entre otros, en marzo y abril de 1703, en octubre de 1705 y febrero de 1706 ante el alivio de los voluntarios presentados. En este caso concreto, no solo se trata de palabras de alabanza para estos, sino que constituye un ejemplo de conciencia de elite distinguiendo claramente a los nobles de los pecheros ${ }^{87}$ en un momento en que la villa encuentra problemas graves para completar el número de soldados que le tocaban. El forzar a los hidalgos llevó a su molestia y se buscó protegerlos aunque fuera para milicias, caso de 1710. Por otro lado, se observa un trato de cariño hacia los gijoneses movilizados fuera del Principado, a los que la villa vigilaba y atendía incluso cuando ya estaban insertos en su unidad de destino. Esto último es muy interesante por dos razones:

a) Gijón mantiene un trato especial con sus naturales.

b) Los soldados de tal origen, no solo sirven a las armas del Rey, sino que representan a la villa y lo que hagan repercute en el buen nombre de la misma.

Como vemos, fue este un campo donde hubo nobles locales que sí respondieron, pero no en número suficiente.

Respecto a la interesante iniciativa de formar una compañía propia en 1703, ciertamente no podemos afirmar que se trate de una actitud realmente comprometida. Es decir, se puede

85 Martínez-Radío, 2009: 149, 204-209. En esta obra se dedica un apartado específico a esta cuestión.

86 A la par que se conforma el Tercio del Principado y respecto a los Tercios Provinciales, se crean ocho nuevos en Galicia a partir de las Compañías de ese Reino y a cargo del Duque de Híjar, Capitán General de Galicia, al año siguiente, y dieciséis más andaluces para relevar a las tropas veteranas estacionadas en Andalucía y encargadas de la guarnición de costas (Gómez Ruiz y Alonso Juanola, 1989: 27 y 28; Parejo Delgado, 2001: 463 y 464).

87 Vid. en este sentido de la nobleza asturiana y el ejercicio militar, Martínez-Radío, 2004: 50- 61. 
sospechar que la villa pretendiera formar una compañía de voluntarios que le sirviera de «comodín». Planteamos las siguientes hipótesis:

a) En caso de que les pidan una contribución de hombres para levas los podría extraer de ella.

b) Con la unidad ya cumpliría aludiendo a que había formado por sí una compañía y dando buena imagen a la Corona y posiblemente se librara de futuras levas.

c) Respecto a los voluntarios, entendemos que tendrían menos posibilidades de ser enviados fuera de Gijón/Asturias, con lo que no arriesgarían tanto en la guerra y «cumplirían» con el espíritu militar pretendido, a lo que sumaríamos la obtención de honra, más un sueldo de soldado, etc. ${ }^{88}$

d) La oficialidad de la compañía del lugar les evitaría además problemas y podría hacer presión para que la unidad se destinara a otro lugar.

Con todo, se detecta en la misma que se prefieren nobles y/o que sea una actividad de distinción social, como se evidencia en los propios testimonios de los voluntarios. Este punto enlaza con la fidelidad de la villa a la causa del Borbón. Pero el año de 1706, ante el llamamiento a frenar el avance austracista y los alistamientos de la elites locales por ellos mismos y sus familiares, dejó claro que muchas veces el patriotismo se puede disolver en palabras, quizás como elemento de reconocimiento, integración social o simple acción de cara al pueblo, aunque a la hora de la verdad quienes cargaban con las cargas de las levas eran los pecheros. Un hecho para dudar de las palabras de bravura, aparte de que finalmente no cumplió ninguno, sería mismamente que hubiera un voluntario con 63 años, que obviamente y teniendo en cuenta las condiciones de vida de la época, poco podría hacer en combate. Otro punto sería que dudamos de que realmente las elites locales tuvieran la intención de sacrificar a todos sus hijos en la guerra, tanto por razones obvias biológicas como padres, como por las económicas y de linaje. Esto, por supuesto, si lo que se trató fue realmente de no dejar la villa sin clase dirigente $\mathrm{y}$, por tanto, desorganizada, aparte de perder sus elites en un momento delicado. No obstante, no dudamos de sus temores, pues en ese año se buscaron pertrechos defensivos desesperadamente, por préstamo, endeudándose o requisándolo, lo cual nos evidencia urgencia. De hecho, el caso de la búsqueda de pólvora en 1703 para armas portátiles, indica que efectivamente pensaban que podía haber un desembarco y combates cercanos más allá de un intercambio de fuego de artillería o bombardeo de la villa. La guerra le supuso un gran gasto que le llevó incluso a endeudarse con particulares o utilizar a los propios vecinos como mano de obra y que facilitaran materiales o medios para la misma.

\section{BIBLIOGRAFÍA}

Adaro Ruiz-Falcó, L. (1979): «El puerto», E. Arce Piniella y J. Antxón F. Lupiáñez (dirs.), El libro de Gijón. Oviedo, Ediciones Naranco: 159-199.

Álvarez-Buylla, J. B. (1970): «Inglaterra», S. Cañada, L. Castañón y J. A. Mases (dirs.), Gran Enciclopedia Asturiana, vol. 8. Gijón, Ed. Silverio Cañada: 225-228.

Bellmunt y Traver, O. (1980): «Luarca», O. Bellmunt y F. Canella (dirs.), Asturias. Gijón, 1897, t. II, reed. en Gijón, Ed. Silverio Cañada: 341-366.

\footnotetext{
88 Porque exponen que lo hacen con las condiciones de esa compañía y no se presentan a la leva del $1 \%$ aludida -parece que la evitan-. Es más, uno que había ya sentado plaza, ahora se presenta voluntario en la compañía de Gijón.
} 
Bonet, J. A. (1970a): Biografia de la villa y puerto de Gijón, vol. I. Gijón, Tip-Offset La Industria.

Bonet, J. A. (1970b): «Gijón», S. Cañada, L. Castañón y J. A. Mases (dirs.), Gran Enciclopedia Asturiana. Gijón, Ed. Silverio Cañada, vol. 7: 221-256.

Campo-Grande, V. de (1916): La Junta General del Principado de Asturias. Bosquejo histórico. Oviedo, Establecimiento Tipográfico La Cruz.

Canella Secades, F. (2000): «Colunga», O. Bellmunt y F. Canella (dirs.), Asturias, t. III. Gijón, 1900, reed. en Gijón, Ed. Silverio Cañada, 2000: 479-488.

Fernández Martín, L. (1977): «Alcaides de las fortalezas reales asturianas, siglos XV- XVII». Boletín del Instituto de Estudios Asturianos, 92: 795-821.

Friera Álvarez, M. (2003): La Junta General del Principado a fines del Antiguo Régimen (1760-1835). Oviedo, Junta General del Principado de Asturias, Consejería de Educación y Cultura, KRK Ediciones.

García San Miguel, J. (1980): «Avilés», O. Bellmunt y F. Canella (dirs.), Asturias, t. I. Gijón, Fototipia y Tipografía de O. Bellmunt, Gijón, 1895, reed. en Gijón, Ed. Silverio Cañada: 196-260.

Gómez Ruiz, M. y Alonso Juanola, V. (1989): El Ejército de los Borbones. 1700-1746. Madrid, Servicio Histórico Militar y Museo del Ejército.

González Llanos y González Llanos, M. (2000): «Gozón», O. Bellmunt y F. Canella, Asturias, t. III. Gijón, Fototipia y Tipografía de O. Bellmunt, 1900, reed. en Gijón, Ed. Silverio Cañada: 97-110.

González Sánchez, I. (2005): «'Rechazar con escarmiento': ofensivas inglesas a Gijón durante el reinado de Carlos III», A. Guimerá Ravina V. Peralta Ruiz (coords.), Actas de la VIII Reunión Científica de la Fundación Española de Historia Moderna: (Madrid, 2-4 de junio de 2004), vol. 2 (El equilibrio de los imperios: de Ultrecht y Trafalgar). Madrid, Fundación Española de Historia Moderna: 661-672.

Martínez-Radío Garrido, E. C. (2018): «Conflicto diplomático en Gijón por un barco portugués», diario La Nueva España (ed. Gijón) de 4 de mayo: 10.

Martínez-Radío Garrido, E. C. (2003): «La Junta General del Principado, la institución militar y la defensa de Asturias en el siglo XVIII», Cátedra General Castaños (ed.), Actas de las XI Jornadas Nacionales de Historia Militar. Sevilla, 11-15 de noviembre de 2002. Milicia y sociedad Ilustrada en España y América (1750-1800), t. I. Madrid, Deimos: 383-402.

Martínez-Radío Garrido, E. C. (2004): «El soldado de Milicias en la Asturias del siglo XVIII», J. Girón (dir.), Historia Militar de Asturias. Oviedo, Real Instituto de Estudios Asturianos: 33-68.

Martínez-Radío Garrido, E. C. (2005): La milicia asturiana en la Guerra de Sucesión. Madrid, Fundación Cultural de la Milicia Universitaria.

Martínez-Radío Garrido, E. C. (2007): «Obligaciones y necesidades en defensa del Principado de Asturias en el tránsito del siglo XVII al XVIII». Revista de Historia Militar, 101: 205-230.

Martínez-Radío Garrido, E. C. (2008a): «La sociedad asturiana y la Guerra de Sucesión», M. Á. Faya Díaz y E. C. Martínez-Radío Garrido (coords.), Nobleza y Ejército en la Asturias de la Edad Moderna. Oviedo, KRK Ediciones: 247-261.

Martínez-Radío Garrido, E. C. (2008b): «Levas y reclutas en la Asturias de la Guerra de Sucesión; el caso del Tercio del Principado». Revista de Historia Militar, 103: 127-166.

Martínez-Radío Garrido, E. C. (2009): La Guerra de Sucesión y Asturias. Oviedo, Consejería de Educación y Turismo del Principado de Asturias y KRK Ediciones.

Martínez-Radío Garrido, E. C. (2013): La organización de las Milicias en Asturias bajo el reinado de Felipe Vy el Regimiento Provincial de Oviedo. Madrid, Ministerio de Defensa.

Menéndez González, A. (1992): Élite y poder: la Junta General del Principado de Asturias. 1594-1808. Oviedo, Instituto de Estudios Asturianos.

Mortera Pérez, A. (2010): Las defensas de la bahía de Gijón. Siglos XVII-XX. Oviedo, KRK Ediciones.

Ovies Ruiz, J. R. (1970): «Avilés», S. Cañada Luciano Castañón y J. A. Mases (dirs.), Gran Enciclopedia Asturiana, vol. 2. Gijón, Ed. Silverio Cañada: 161-196.

Parejo Delgado, M. J. (2001): «Las ordenanzas militares durante la Guerra de Sucesión», Cátedra General Castaños (ed.), La Guerra de Sucesión en España y América. Actas de las X Jornadas Nacionales de Historia Militar. Sevilla, 13- 17 de noviembre de 2000. Madrid, Deimos: 461-480.

Pérez de Rada, J. (1999): Relación de los poseedores del Castro y Palacio de Priaranza del Bierzo de alguno de sus allegados y descendencia de ellos. Madrid, Fundación Jaureguízar. 
Peribáñez Caveda, D. (2010): «Gijón en la Edad Moderna», J. Rodríguez Muñoz (dir.), Historia de Gijón, vol. 6. Oviedo, Editorial Prensa Asturiana: 95 pp.

Porras Gil, C. (1995): Organización defensiva española en los siglos XVI y XVII, desde el río Eo hasta el valle de Arán. Valladolid, Universidad de Valladolid, Secretariado de Publicaciones.

Rato y Roces, C. (1980): «Gijón», O. Bellmunt y F. Canella (dirs.), Asturias, t. I. Gijón Fototipia y Tipografía de O. Bellmunt, 1895, reed. en Gijón, Ed. Silverio Cañada: 131-195.

Rendueles Llanos, E. (1867): Historia de la villa de Gijón desde los tiempos más remotos hasta nuestros días. Gijón, Imprenta de El Norte de Asturias.

Samaniego Burgos, J. A. (1979): «Monumentos», E. Arce Piniella y J. A. F. Lupiáñez (dirs.), El Libro de Gijón. Oviedo, Ediciones Naranco: 225-261.

Suárez-Inclán, M. P. (1970): «Gozón», S. Cañada, L. Castañón y J. A. Mases (dirs.), Gran Enciclopedia Asturiana, vol. 8. Gijón, Ed. Silverio Cañada: 2-24.

Tuero Bertrand, F. (1976): Instituciones tradicionales en Asturias. Salinas, Ayalga.

Tuero Bertrand, F. (1978): La Junta General del Principado. Salinas, Ayalga, Colección Popular Asturiana.

Villa, M. de la (1909): La Junta General del Principado de Asturias. Oviedo, Establecimiento Tipográfico de Uría Hermanos.

Recibido: 13-12-2017

Aceptado: 04-06-2018 